\title{
STATIC ANALYSIS OF THE CYLINDRICAL TANK RESTING ON VARIOUS TYPES OF SUBSOIL
}

\author{
Zora Mistríková ${ }^{1}$, Norbert Jendželovský ${ }^{2}$ \\ Department of Structural Mechanics, Faculty of Civil Engineering, Slovak University of Technology, \\ Radlinskeho str. 11, 81368 Bratislava, Slovak Republic \\ E-mails: ${ }^{1}$ zora.mistrikova@stuba.sk (corresponding author); ${ }^{2}$ norbert.jendzelovsky@stuba.sk \\ Received 22 Jul. 2010; accepted 22 Nov. 2011
}

\begin{abstract}
The paper presents analyses of deformations and stress of the circular rotationally symmetric tanks. The reinforced concrete tanks - water reservoirs - resting on elastic subsoil have been analyzed. The elastic subsoil has been modeled using three basic subsoil models: half-space model, two-parametric model and one-parametric (Winkler) subsoil model. Particular modifications have been applied to the basic models which yield in seven models presented. The cylindrical tank has been analyzed in the interaction with the subsoil, while the elastic subsoil has been characterized by different parameters. The differences in modeling using individual calculation models have been highlighted. The results from analytical and numerical solutions have been presented and compared in graphs and tables. The method for the calculation of settlement of the circular foundation plate was verified experimentally. The settlement of the circular plate was measured while the silo was fully loaded by its contents. The experimentally obtained values have been compared with the calculation results. In the conclusion the recommendations for the suitable model subsoil for these types of structures have been presented.
\end{abstract}

Keywords: FEM, structure-subsoil interaction, symmetric water tank.

\section{Introduction}

Cylindrical tanks, especially those made of the reinforced concrete, are building structures that have been frequently used e.g. in water management (water reservoirs, sewage plants, digestion tanks), and in industry (for storage of chemical agents). The rotational symmetry can be taken into account during calculations of such structures, as they are most usually loaded by dead weight and pressure from fluid or soil on the foundation plate and wall of the tank.

In this work, the deformations and internal forces of the cylindrical tank with an open upper end in the contact with subsoil are analyzed. The subsoil has been introduced into the calculations by means of three basic subsoil models: half-space model, two-parametric model and one-parametric (Winkler) subsoil model. Each model has following particular modifications:

1. Half-space has been modeled as:

- large-volume solid with constant active deformation depth;

- large-volume solid with active deformation depth depending on the contact stresses;

- infinite half-space.

2. Two-parametric model has been modeled:

- with given constant parameters $C 1, C 2$;

- with parameters $C 1, C 2$ obtained from geological layers and from the active deformation depth.
3. One-parametric (Winkler) model has been modeled:

- with constant parameter $c$;

- as the modified Winkler subsoil model.

For the analysis of deformation and stress of cylindrical tank in the contact with the above mentioned subsoil models, software created by authors as well as the ANSYS (2009) and NEXIS software (2006) systems were used. Particular physical models of subsoil corresponding to the mathematical solution of the contact between the cylindrical tank and the subsoil were labeled as $(\mathrm{n} 1) \div(\mathrm{n} 7)$ and they are presented below.

\section{Definition of subsoil models. Methods of solution of interaction between the cylindrical tank and the subsoil}

The cylindrical tank has been analyzed in interaction with various physical models of subsoil, using several numerical and analytical methods, namely: FEM, collocation (force-deformation) method; and by means of the direct solution of differential equations.

\subsection{The subsoil modeled as the half-space}

\subsubsection{Model (n1)}

Half-space model (n1), Fig. 1, represents the large-volume solid. Its height depends on the active deformation depth. Some detailed calculations of the active deformation depth have been presented in Kuklík et al. (2009), Rasiulis and 
Gurkšnys (2010). The active deformation depth is constant and the subsoil is modeled by finite elements BRICK in the model (n1). It is the 8-node element with three nodal displacements. Material characteristics of particular finite elements correspond to the characteristics of subsoil, which can be either homogeneous or layered.

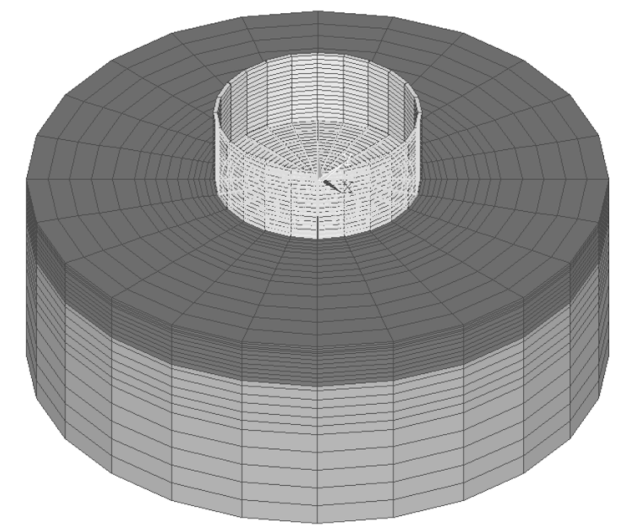

Fig. 1. Model of the cylindrical tank and the subsoil

In the analysis of the rotationally symmetric problem the subsoil is modeled as the cylinder-shaped large solid while the following boundary conditions are fulfilled:

- in the bottom part of the cylinder located in the active depth, all three displacements $(u, v, w)$ are of zero value;

- in the external wall of the cylinder, the displacement in the direction normal to the cylinder surface is of zero value;

- the structure of the reinforced tank is modeled by 4-node shell element. In each node there are 6 displacement units. Both the circular plate and the walls of the cylindrical tank are modeled using these shell elements.

Special attention should be paid to the coupling between the concrete circular plate and the subsoil. Contact elements have been used for its modeling to provide primarily the compatibility of vertical displacements.

\subsubsection{Model (n2)}

Half-space model (n2) is identical with the model (n1) except for its active deformation depth assessment. The active deformation depth has been considered constant for the entire model (n1) while in model (n2) the active deformation depth has been analyzed in two steps. In the first step, the deformation depth is the same as in model (n1). The vertical stress from the additional load of structure in particular points of the subsoil is calculated. Also the original stress from the soil pressure is evaluated for these points and the values are compared. If the geostatic pressure in particular point is higher than the stress from the additional load, the boundary condition - zero vertical displacement - must be introduced for that particular point of subsoil. Such a calculation has to be performed for all the internal points of the subsoil.

The deformation zone is not a plane surface, as the subsoil below the tank structure is compressed within the dish-shaped area. In the second step new boundary conditions have been introduced into the calculation of contact stress, deformations and internal forces of the circular plate and the cylindrical tank.

\subsubsection{Model (n4)}

Physical model of the infinite homogeneous half-space (n4) is characterized by two independent material characteristics $E_{p}, v_{p}$ (Fig. 2). The combined mathematicalphysical model is based on the Boussinesque's solution of the infinite half-space. The interaction of the wall of cylindrical tank with the circular rotationally symmetrical plate and the infinite half-space has been solved using the numerical force-deformation method.

The unknown contact stress between the circular plate and the half-space has been assumed constant at the surfaces of the rings. The continuous interaction forces between the wall of cylindrical tank and the circular plate are constant as well. The strain and stress of the circular plate and the cylindrical tank have been solved by analytical solution of the differential equations for bending of the circular plate and the tank wall. The solution is evident from the Fig. 2 and it was described in detail in Mistríková $(2008,2009)$.

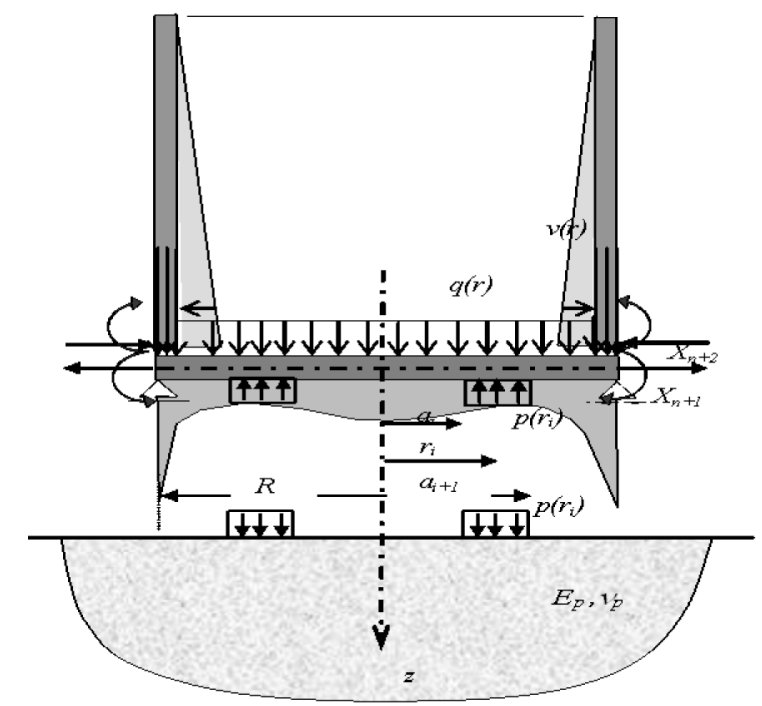

Fig. 2. Model of the cylindrical tank

\subsection{Two-parametric models}

Interaction between the cylindrical tank and the twoparametric subsoil model has been solved using the numerical method - FEM. The contribution of the subsoil potential energy to the overall potential energy of the system: cylindrical tank + subsoil is following for the two-parametric subsoil model:

$$
\begin{gathered}
\pi_{p}=\frac{1}{2} \int_{\Omega}\left[C_{1 z} w_{o}^{2}(x, y)+C_{2 x}\left(\frac{\partial w_{0}(x, y)}{\partial x}\right)^{2}+\right. \\
\left.C_{2 y}\left(\frac{\partial w_{0}(x, y)}{\partial y}\right)^{2}\right] d \Omega,
\end{gathered}
$$


where parameters $C_{l z}=C_{l z}(x, y) \quad\left(\mathrm{N} / \mathrm{m}^{3}\right) \quad$ and $C_{2 x}=C_{2 y}=C_{2 x}(x, y)(\mathrm{N} / \mathrm{m})$ represent the compressibility and the shear distribution of the subsoil. $w_{o}(x, y)$ is the deflection area of the subsoil surface in the domain $\Omega$. It is obvious that the expression Eq. (1) is fairly dependent on the numerical values of the coefficients $C_{l z}$ and $C_{2 x}=C_{2 y}$ and the domain $\Omega$. Models (n3) and (n7) differ just in input values of these coefficients. In both models the interaction problems have been analyzed using the NEXIS software (2006).

\subsubsection{Model (n3)}

In this model, the interaction problem has been analyzed using the software NEXIS (2006), module SOILIN, where the subsoil parameters $C_{l}$ and $C_{2}$ have been specified from the given geological characteristics of the subsoil. The module SOILIN performs the conversion from the 3-D solid having the volume $V=\Omega H$ to the surface model with the area $\Omega$. This conversion is described in detail in Koláŕ and Němec (1986) and Vlasov and Leontiev (1960). Parameters $C_{l z}=C_{l z}(x, y)$ and $C_{2 x}=C_{2 y}=$ $C_{2 x}(x, y)$ depend on the value of the contact stress between a circular plate and the subsoil and on the depth $H$ of vertical deformation dissipation. To obtain the parameters, iterations have been performed as long as either contact stress or the vertical displacement differ by specified value in two successive iterations. The depth $H$ of the dissipation is the same as the active deformation depth defined according to the Slovak National Standard STN 731001 (2010). Due to the effects of the shear stress $\tau_{z x}$ and $\tau_{z y}$ the settlement of the subsoil surface occurs in a circular segment even off the foundation gap. Hence the circular segment is modeled using SOILIN module by means of finite elements with zero stiffness. The wall of the cylindrical tank is modeled using the shell elements.

\subsubsection{Model (n7)}

In the model (n7) the parameters $C_{1}$ and $C_{2}$ are constant below the whole circular plate. Effects of the segment of surrounding subsoil off the cylindrical tank's foundation plate were substituted by introducing the spring constant $k_{w}$, which is continuously distributed along the circumference of the circular plate. Its value is determined from the Eq. (2):

$$
k_{w}=\sqrt{C_{l} C_{2}} \frac{K_{l}\left(\rho_{0}\right)}{K_{0}\left(\rho_{0}\right)},
$$

where $K_{l}\left(\rho_{0}\right)$ and $K_{0}\left(\rho_{0}\right)$ are Bessel's functions for $\rho_{0}=\frac{R}{S} . K_{l}(\rho)$ and $K_{0}(\rho)$ are the results of the differential equation for the deflection area of surface of two-parametric subsoil from the load at the circular domain with radius $R . s=\sqrt{C_{2} / C_{1}}$ is the characteristic length for two-parametric subsoil. It has been presented e.g. in Kolář and Němec (1986) and Pasternak (1954).

\subsection{One-parametric models}

In these two models the interaction problem has been solved on one-parametric (Winkler) subsoil model using the numerical method - FEM and the software NEXIS (2006).

\subsubsection{Model (n5)}

Model (n5) is the standard one-parametric (Winkler) subsoil model with compressibility coefficient $c\left(\mathrm{~N} / \mathrm{m}^{3}\right)$ which is constant below the whole circular plate of the cylindrical tank.

\subsubsection{Model (n6)}

Model (n6) is modified Winkler subsoil model. The disadvantage of the one-parametric model (neglecting the deformation off the foundation plate) is here partially compensated by introducing higher subsoil stiffness along the circumference of the plate. Higher subsoil stiffness is modeled as the continuous spring along the circumference of the plate. The deformation and stress problems of the plate resting on the Winkler or modified Winkler subsoil have been dealt with, e.g., in Karamanski and Kazakov (2005). The authors in this work have defined the higher stiffness of the subsoil below the edge of the foundation plate according to Vlasov and Leontiev (1960) and Cytovič (1983), from the energy of the deformation of twoparametric subsoil off the foundation plate. In this particular problem the spring stiffness was defined according to the two-parametric subsoil model by Vlasov and Leontiev (1960). Then the reaction of subsoil $Q(R)$ along the circumference of the circular plate is following:

$$
Q(R)=w(R) \sqrt{2 t k} \frac{K_{l}(\alpha R)}{K_{0}(\alpha R)},
$$

where:

$$
\begin{gathered}
k=\frac{E_{p}}{\left(1-v_{p}^{2}\right)_{0}^{H} \chi^{\prime 2}(z) d z,} \\
t=\frac{E_{p}}{4\left(1-v_{p}\right)} \int_{0}^{H} \chi^{2}(z) d z, \\
\alpha=\sqrt{\frac{k}{2 t}} .
\end{gathered}
$$

Function $\chi(z)$ is the function of the vertical displacement dissipation to the depth $H$. According to Vlasov and Leontiev (1960), it depends on the subsoil properties. It can be e.g. of the shape of the linear function (Eq. (5)):

$$
\chi(z)=\frac{H-z}{H} .
$$

If the parameters are denoted $C_{2}=2 t, C_{l}=k$ (Koláŕ, Nĕmec 1986), then for the response of the surrounding subsoil acting at the edge of plate (Eq. (3)) it is valid:

$$
Q(R)=w(R) k_{w},
$$

where $k_{w}$ is obtained from the expression in Eq. (2). 


\section{Numerical analysis}

Let us consider the reinforced tank resting on the layered subsoil with geometrical and material characteristics presented in Fig. 3.

The cylindrical tank wall and the foundation plate are made of the concrete $\mathrm{C} 20 / 25$ (B25) $(\mathrm{E}=30000 \mathrm{MPa}$, $\left.v=0.15, \rho=25000 \mathrm{~kg} / \mathrm{m}^{3}\right)$.

The subsoil layers were defined by geologist having the following characteristics:

$$
\begin{aligned}
& \mathrm{F}_{3} \quad\left(\mathrm{E}_{\mathrm{def}}=5000 \mathrm{kN} / \mathrm{m}^{2}, v=0.35, \gamma=18 \mathrm{kN} / \mathrm{m}^{3},\right. \\
& \mathrm{m}=0.2, \beta=0.62) ; \\
& \mathrm{F}_{8}\left(\mathrm{E}_{\mathrm{def}}=2000 \mathrm{kN} / \mathrm{m}^{2}, v=0.42, \gamma=20.5 \mathrm{kN} / \mathrm{m}^{3},\right. \\
& \mathrm{m}=0.2, \beta=0.37) ; \\
& \mathrm{G}_{2}\left(\mathrm{E}_{\mathrm{def}}=12000 \mathrm{kN} / \mathrm{m}^{2}, v=0.2, \gamma=20 \mathrm{kN} / \mathrm{m}^{3},\right. \\
& \mathrm{m}=0.3, \beta=0.90) .
\end{aligned}
$$

\subsection{Input characteristics of the subsoil for particular models}

Models (n1), (n2)

In ANSYS software, particular layers of the subsoil have been assigned the above mentioned material constants according to results of the geological survey.

The active depth of the model (n1) is considered constant at the level of $9 \mathrm{~m}$ below the foundation gap. The active depth of the model (n2) is variable. Process of obtaining its values is presented in Chapter 2.1.2.

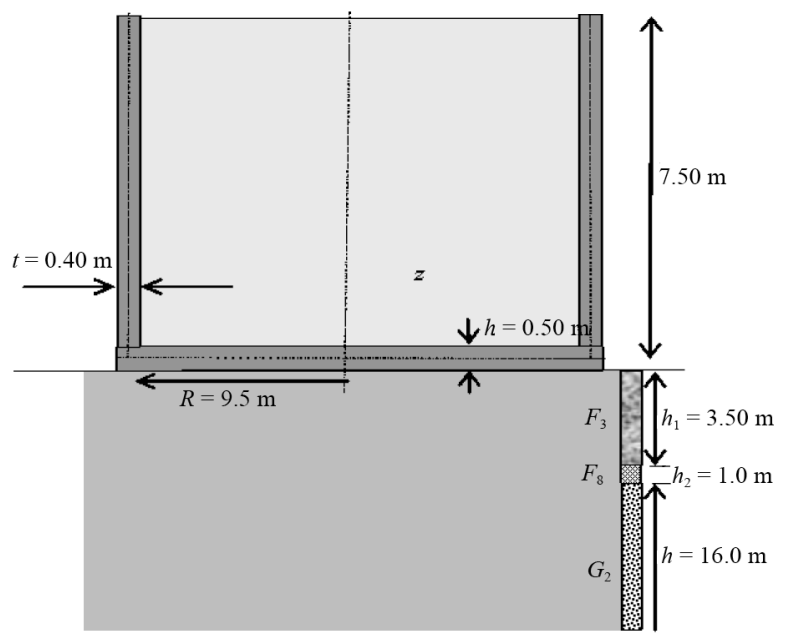

Fig. 3. The rotationally symmetric tank

\section{Model (n4)}

Let us consider the homogeneous subsoil with elasticity modulus $E$ and Poisson's ratio $v$. The elasticity modulus $E$ was obtained in a following way: the settlement below the centre of the loaded circular domain was calculated according to Eq. (7) (taken from STN 731001 2010). In this relation the layers $i$ of subsoil have been taken into account:

$$
s=\sum_{i=1}^{n} \frac{\sigma_{z, i}-m_{i} \sigma_{o r, i}}{E_{o e d, i}} h_{i},
$$

$$
\text { if } \quad \sigma_{z, i}-m_{i} \sigma_{o r, i} \geq 0 .
$$

$\sigma_{z, i}$ (Eq. (8)) is the vertical normal stress in the $i^{\text {th }}$ layer below the centre of the loaded circular domain with load $q\left(\mathrm{kN} / \mathrm{m}^{2}\right)$ and radius $R(\mathrm{~m}), q$ is the load equal to the weight of the tank filled with water (Fig. 3):

$$
\sigma_{z, i}=q\left[1-\frac{z^{3}}{\left(z^{2}+R^{2}\right)^{\frac{3}{2}}}\right] .
$$

In Eq. (7) $\sigma_{o r, i}$ is the original geostatic stress in the centre of the $i^{\text {th }}$ layer, $E_{\text {oed }, i}$ is the oedometric module of the $i^{\text {th }}$ layer, $m_{i}$ is the coefficient of the structural strength mentioned in (STN 731001 2010).

Eq. (9) represents the vertical deformation in the centre of the circular domain at the half-space surface:

$$
w_{s}=\frac{2 q R\left(1-v^{2}\right)}{E} .
$$

Values $s$ from Eq. (7) and $w_{s}$ from Eq. (9) were compared and the elasticity modulus $E=27620 \mathrm{kPa}$ was obtained. The Poisson's ratio was considered $v=0.32$. These values have been used for this calculation model. Using the Eq. (7) the obtained active deformation depth is $10.5 \mathrm{~m}$.

\section{Model (n3)}

As it was mentioned in the Chapter 2.2.1., for SOILIN module the subsoil parameters $C_{1}$ and $C_{2}$ have been specified from the given geological characteristics of the subsoil. Calculations of $C_{1}, C_{2}$ and analysis of interaction between the cylindrical tank and the subsoil have been performed in iteration steps. In our analysis, the calculation was completed in 3 iteration steps. The values of the subsoil parameters below the circular plate domain, depending on the value of the contact stress, ranged in following intervals: for $C_{1 z} \in(1703 \div$ $2350) \mathrm{kN} / \mathrm{m}^{3}$, for $\mathrm{C}_{2 \mathrm{x}}=\mathrm{C}_{2 \mathrm{y}} \in(2500 \div 3400) \mathrm{kN} / \mathrm{m}$. The active deformation depth $h$ depends on the contact stress as well, and ranges in the interval $H \in(7.3 \div 9.4) \mathrm{m}$. Values close to the left side of the interval are below the circular plate, values close to the right side of the interval correspond to the edge of the circular plate.

\section{Model (n7)}

Let us consider the parameters to be constant below the whole domain of the circular plate. They have been calculated by Eqs (10) and (11) taken from Kolár and Němec (1986). Substitute parameters for subsoil layers presented in Fig. 3 are following: $C_{1}=1035 \mathrm{kN} / \mathrm{m}^{3}, C_{2}=$ $5050 \mathrm{kN} / \mathrm{m}$. The spring constant along the circumference of the circular plate by Eq. (2) is $\mathrm{k}_{\mathrm{w}}=2678 \mathrm{kN} / \mathrm{m}^{2}$ :

$$
C_{l}=\frac{1}{\sum_{i=1}^{n} \frac{1}{C_{l, i}}},
$$




$$
\begin{gathered}
C_{2}=\frac{C_{l}^{2}}{6} \sum_{i=1}^{n}\left\{\frac { E _ { i } h _ { i } } { ( 1 + v _ { i } ) } \left[\left(\sum_{j=i}^{n} \frac{1}{C_{l, j}}\right)^{2}+\right.\right. \\
\left.\left.+\left(\sum_{j=i}^{n} \frac{1}{C_{l, j}}\right)\left(\sum_{j=i+l}^{n} \frac{1}{C_{l, j}}\right)+\left(\sum_{j=i+l}^{n} \frac{1}{C_{l, j}}\right)^{2}\right]\right\},
\end{gathered}
$$

where Eq. (11) represents the auxiliary layer constants:

$$
C_{l, i}=\frac{E_{i}\left(1-v_{i}\right)}{h_{i}\left(1+v_{i}\right)\left(1-2 v_{i}\right)} .
$$

\section{Model (n5)}

The compressibility coefficient $c$ below the circular plate has been defined from the relation $c=q / s$, while $s=41.67 \mathrm{~mm}$ was obtained from the settlement of the characteristic point of the domain circularly loaded by uniform load $q$ (Eq. (7)). For the whole domain $c=$ $2087.44 \mathrm{kN} / \mathrm{m}^{3}$.

\section{Model (n6)}

For the modified Winkler model the compressibility coefficient $c$ below the circular plate was defined (likewise in model (n5)) from the relation $C=q / s$, while $s=52.53 \mathrm{~mm}$ was obtained from Eq. (7) - the settlement of the centre of the circularly loaded domain $q$. For the whole domain $c=1657 \mathrm{kN} / \mathrm{m}^{3}$. Higher stiffness of subsoil below the plate edge is represented by the spring with value $\mathrm{k}_{\mathrm{w}}=2784.9 \mathrm{kN} / \mathrm{m}^{2}$. It was obtained from Eqs (2), (10), (11), and from Kolár and Němec (1986), where $k=C_{1}=$ $1035 \mathrm{kN} / \mathrm{m}^{3}, 2 t=C 2=5050 \mathrm{kN} / \mathrm{m}$. The Bessel's functions quotient $K_{l}\left(\rho_{0}\right) / K_{0}\left(\rho_{0}\right)$ for $\rho_{0}=R / s$ is 1.17 .

\section{Analysis of results}

In the Figs 4-10 there are presented the internal forces and the deformations of the circular plate and the cylindrical tank wall observed in above mentioned models (n1) $\div(\mathrm{n} 7)$.

As it is obvious from the graph in the Fig. 4, the curvatures of the deflection areas are nearly the same, except for Winkler subsoil model (n5). The vertical displacements differ in the value of the settlement of circular plate as the rigid body. The settlement depends primarily on the selected parameters specifying the subsoil characteristics. The reverse curvature of the deflection area in the model (n5) consists in the essential feature of this model - neglecting the subsoil deformation off the foundation plate.

The graphs in the Fig. 5 present the curves of radial moments $(\mathrm{kNm} / \mathrm{m})$ in the foundation plate. One can see that the reverse curvature of the deflection area in the model (n5) induces the reverse radial moments. Due to different approaches in modeling of the rigid corner in FEM, the values of radial moments are variable for the place of the joint of the foundation plate into the cylindrical tank wall. In the model (n4) which is a result of the analytical solution of the circular plate and the cylindrical tank, the right-angle between the plate and the tank wall is observed.

Fig. 6 presents axial moments in the foundation plate. For the radial moments and the axial moments, the same conclusions are valid.

In the Fig. 7 the contact stresses in the foundation gap are presented. From the graphs it is obvious that the stress peaks are at the edges of the plate, which also corresponds to the real values obtained from in-situ measurements. The peaks are highest in the elastic half-space models (n1), (n2), and (n4). Their intensity depends on the meshing of the contact area to the finite elements (models (n1), (n2)), or to ring areas (model (n4)).

The graphs in the Figs 8, 9 and 10 present the deformations and internal forces in the cylindrical tank wall. Horizontal displacements of the cylindrical tank wall are shown in Fig. 8. One can see fairly good match between particular models including model (n5).

Bending moments and the membrane forces along the height of the cylindrical tank wall are graphically presented in the Figs 9 and 10. In model (n5) the difference can be observed in the extreme values of the membrane forces and the bending moments having the opposite signs along the height of the cylindrical tank wall.

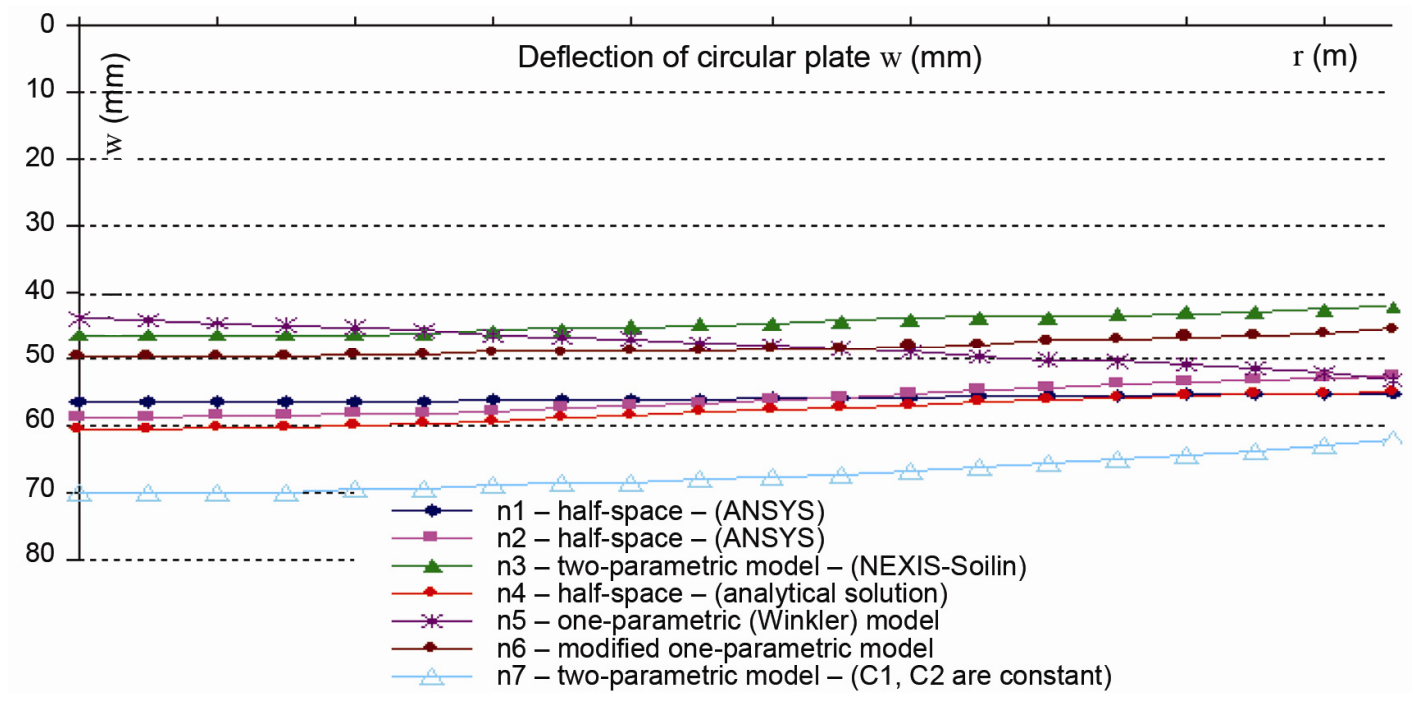

Fig. 4. Vertical deformation of the circular plate 


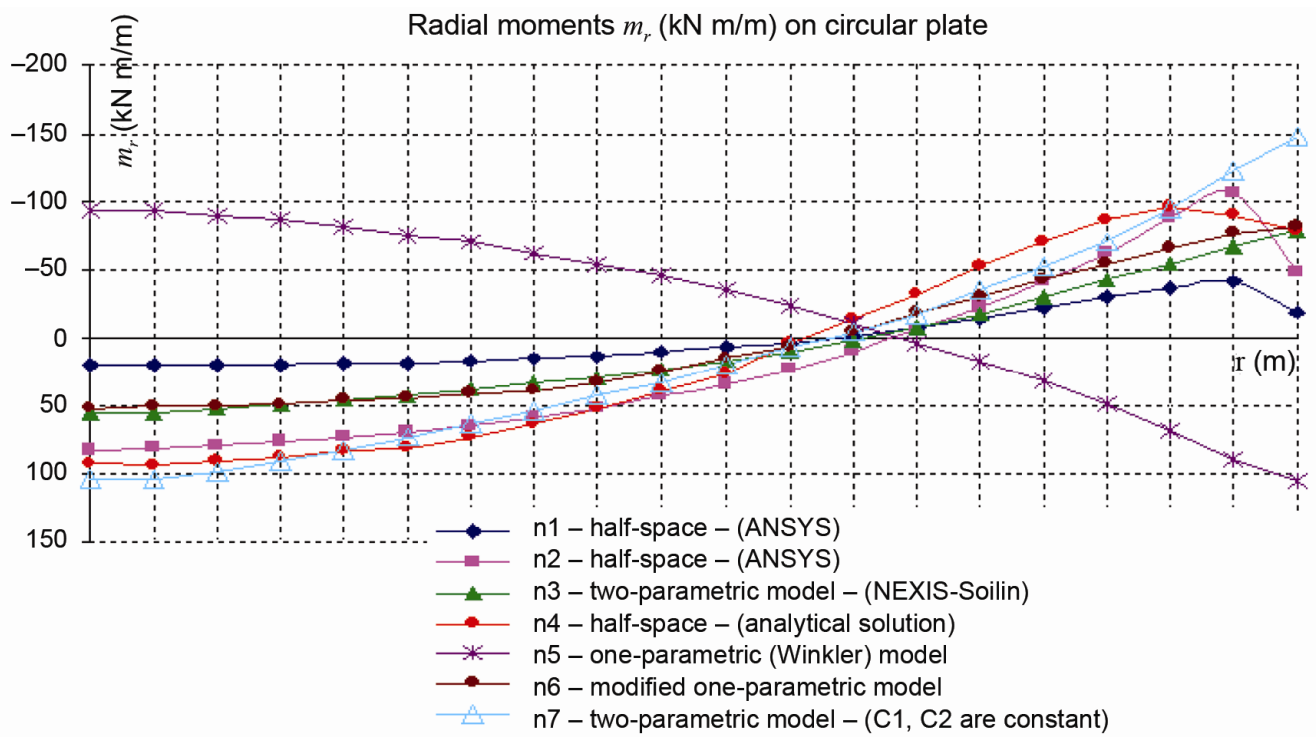

Fig. 5. Radial moments

Axial moments $m_{\div}(\mathrm{kN} \mathrm{m} / \mathrm{m})$ on circular plate

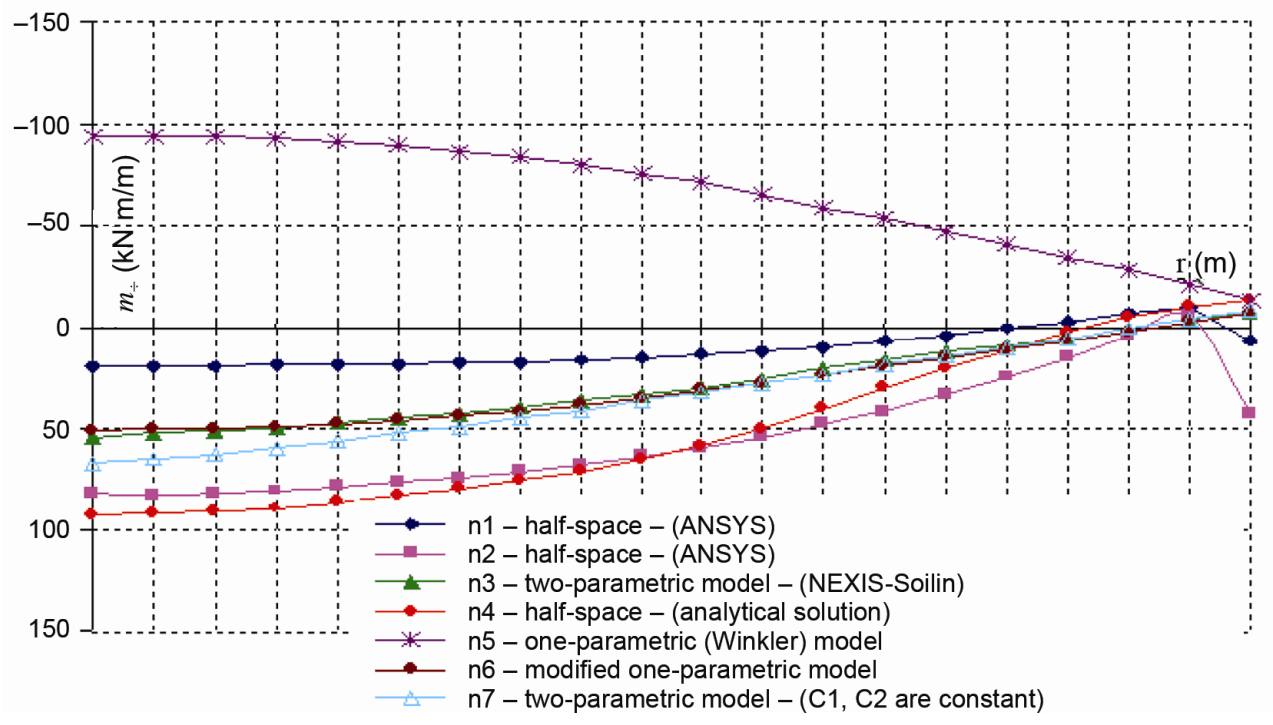

Fig. 6. Axial moments

Contact stress $p(\mathrm{kPa})$

$r(m)$

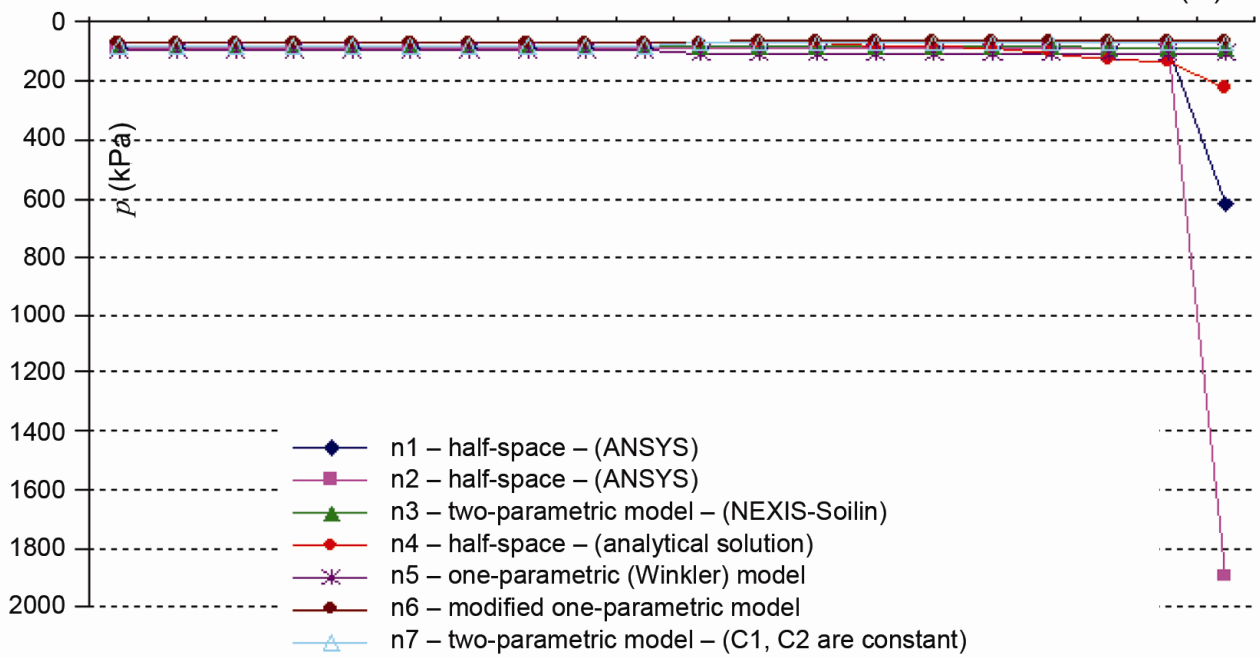

Fig. 7. Contact stress 


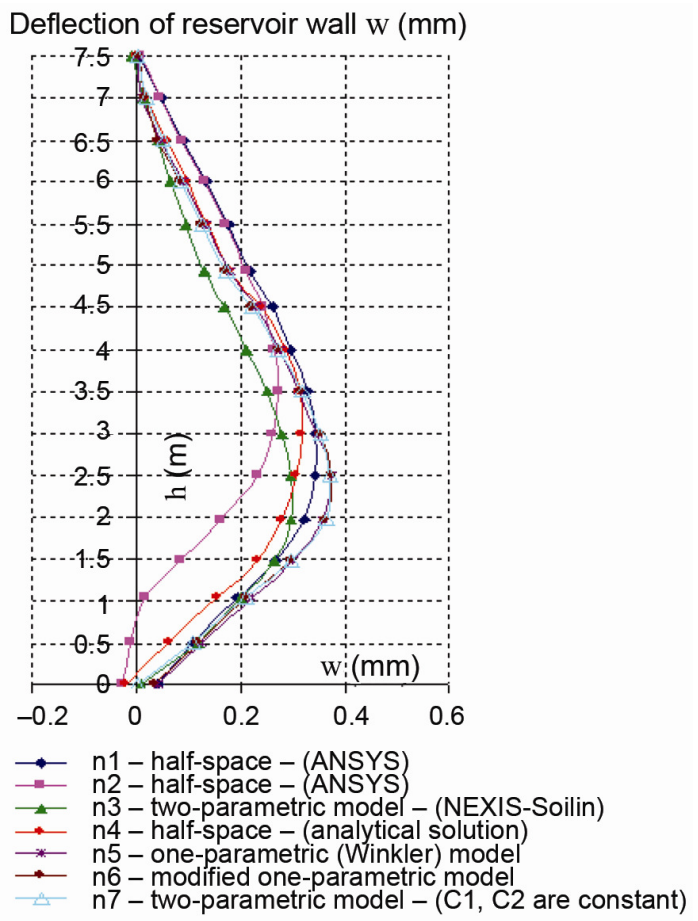

Fig. 8. Horizontal displacements of the wall

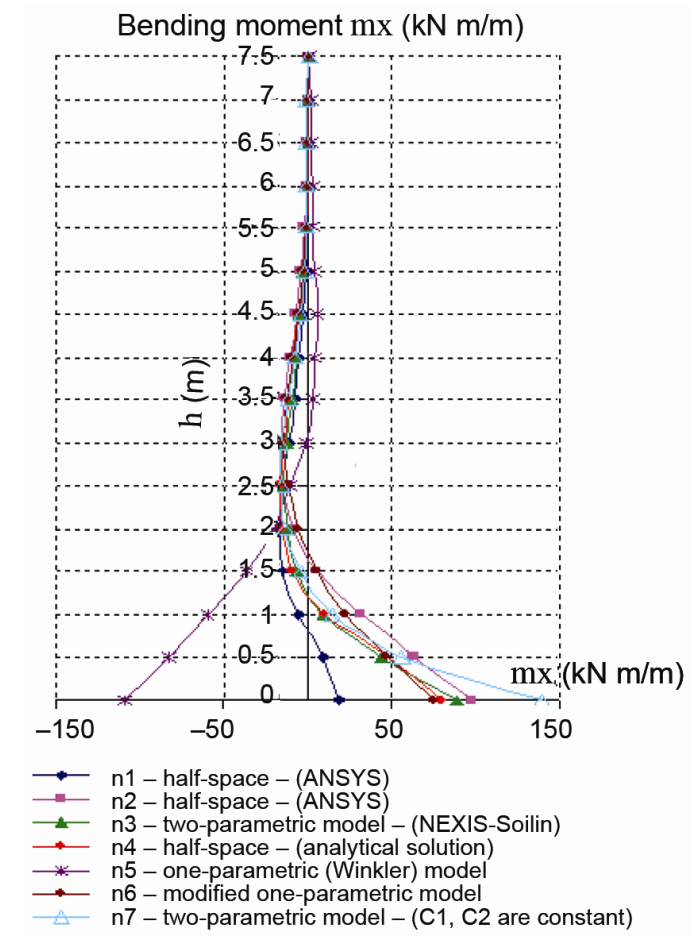

Fig. 9. Bending moments along the cylindrical tank walls

Table 1. Results of the measurements

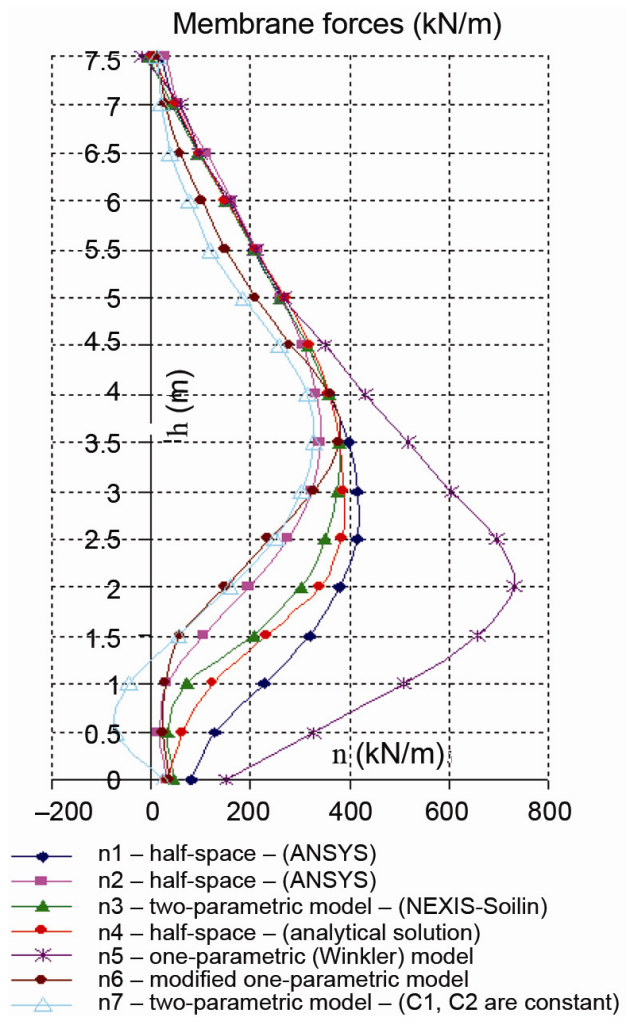

Fig. 10. Membrane forces

\section{Experimental measurement of settlement}

Experimental measurement of settlement of the circular foundation plates below the steel silo was made and evaluated to verify the above mentioned calculations. The silo of the cylindrical shape has following parameters: diameter $32.6 \mathrm{~m}$; height $27.14 \mathrm{~m}$; volume capacity $22653.5 \mathrm{~m}^{3}$.

The steel structure of silo is covered by a conical roof in the height $36.44 \mathrm{~m}$. The weight of the contents (the dried maize) can be max. 18349.3 tons. The reinforced foundation plate of diameter $16.3 \mathrm{~m}$ is $1.0 \mathrm{~m}$ thick. On its top there are concrete ribs that reinforce the plate. Between particular ribs there are spaces that have been used for the transport of the contents. The pressure of the storied mass on the circular foundation is $219.8 \mathrm{kPa}$.

Original subgrade $3.0 \mathrm{~m}$ thick was composed of clay that was removed and replaced by high quality vibrated gravel with the elasticity modulus $\mathrm{E}_{\mathrm{def}}=100 \mathrm{MPa}, v=$ 0.3 . Below the modified layer of subgrade there is an original ground consisting of gravels having the elasticity modulus $\mathrm{E}_{\text {def }}=80 \mathrm{MPa}, v=0.3$.

When the construction was complete, the altitudes of four monitored points were measured. The monitored points were in the peaks of particular circle quadrants.

\begin{tabular}{c|c|c|c|c|c|c}
\hline & \multicolumn{3}{|c|}{ Silo 1 } & \multicolumn{3}{c}{ Silo 2 } \\
\hline Node & Without Loading & Under Loading & Settlement & Before Loading & After Loading & Settlement \\
\hline 1 & 142.674 & 142.661 & $13 \mathrm{~mm}$ & 142.648 & 142.638 & $10 \mathrm{~mm}$ \\
\hline 2 & 142.633 & 142.621 & $12 \mathrm{~mm}$ & 142.647 & 142.633 & $14 \mathrm{~mm}$ \\
\hline 3 & 142.624 & 142.612 & $12 \mathrm{~mm}$ & 142.672 & 142.660 & $12 \mathrm{~mm}$ \\
\hline 4 & 142.620 & 142.605 & $15 \mathrm{~mm}$ & 142.628 & 142.616 & $12 \mathrm{~mm}$ \\
\hline Average & & & $13 \mathrm{~mm}$ & & $14 \mathrm{~mm}$ \\
\hline
\end{tabular}


After additional loading of the silo by the filling, new measurements were made. Results of the measurements are presented in the Table 1 . Here the final values of settlement due to the loading by the silo contents are calculated. The measurements were made by experts - geodesists. In the following, measurements of two silos have been presented:

Next, the structure was numerically modeled in the interaction with the subgrade. Using individual models (n1)(n7) the settlement of the circular plate at its edge was calculated. Comparison of the results of the calculation with the experimentally obtained values is presented in Table 2 .

Table 2. Comparison of the results of the calculation with the experimentally obtained values

\begin{tabular}{c|l|c}
\hline & & Settlement \\
\hline Silo 1 & Experiment & $13 \mathrm{~mm}$ \\
\hline Silo 1 & Experiment & $14 \mathrm{~mm}$ \\
\hline Model n1 & Calculation & $17.52 \mathrm{~mm}$ \\
\hline Model n2 & Calculation & $16.41 \mathrm{~mm}$ \\
\hline Model n3 & Calculation & $11.81 \mathrm{~mm}$ \\
\hline Model n4 & Calculation & $17.10 \mathrm{~mm}$ \\
\hline Model n5 & Calculation & $11.49 \mathrm{~mm}$ \\
\hline Model n6 & Calculation & $12.33 \mathrm{~mm}$ \\
\hline Model n7 & Calculation & $18.21 \mathrm{~mm}$ \\
\hline
\end{tabular}

Results from the experiment and from the numerical analysis showed good agreement. Feasibility of using the mathematical-physical models (n1)-(n7) for analysis of interaction between the structure and the subgrade was proved.

\section{Conclusions}

As it was mentioned above, numerical calculations of the interaction between the structure and the subgrade were modeled using FEM. Cylindrical concrete tank was modeled by shell square finite elements with six degrees of freedom in a node. Total amount of finite elements was 816. In the models (n1) and (n2), entire subgrade was modeled by 3D finite elements of "Brick" type. Total amount of "Brick" finite elements was 17 952. Overall 57357 equations with wave front 201 were used.

Correct assessment of the parameters representing the subsoil characteristics is very important for proper selection of physical models for modeling the interaction between the structure and the subsoil. In regard to the tank structure, where heavy ring load occurs along the circumference of the circular foundation plate, it is necessary during the calculation to consider the acting of the surrounding subsoil near the foundation plate. Neglecting the deformation off the foundation plate in the Winkler model (n5) resulted in different values obtained if compared to other models.
For this type of structure we recommend to choose such a mathematical-physical model, which considers the effects of subsoil off the structure, too. The most unsuitable proved to be the Winkler model (n5) and the modified Winkler model (n6). For the engineering practice and quick obtaining of results, two-parametric models are adequate. For the research purposes, the elastic half-space model is most favourable. It is sophisticated, hence requires rich theoretical background and much time for proper modeling.

\section{Acknowledgements}

The authors gratefully acknowledge the support provided by Slovak Grant Agency VEGA within the project No. $1 / 0629 / 12$.

\section{References}

ANSYS. 2009. User's Manual for Revision 5.4. Volume I-IV, Swanson Analysis System, Inc. 200 p.

Cytovič, N. A. 1983. Mekhanika gruntov [Mechanics of Solids]. Moskva: Vysshaia shkola. 149 p.

Karamanski, T.; Kazakov, K. 2005. Modified model of plate based on the Winkler foundation, in A. Brebbia and G. M. Carlomagno. Computational Methods and experimental Measurements XII, Modelling and Simulation, Vol. $4.7 \mathrm{p}$.

Kolář, V.; Němec, I. 1986. Studie nového modelu podloži staveb [Study of the New Model of Building Subsoil]. Prague: Academia. $188 \mathrm{p}$.

Kuklík, P.; Kopáčková, M.; Brouček, M. 2009. Elastic layer theory and geomechanics. CTU Reports, Vol. 13. Prague: ČVUT. 109 p.

Mistríková, Z. 2008. Circular plate rested on various types of subgrade, in International VSU Conference, 29-30 May, 2008, Sofia, Bulgaria, Vol. I, 73-77.

Mistríková, Z. 2009. Interaction of cylindrical reservoir with various types of subgrade, in Proc. of the International Scientific Conference, 20-22 April, 2009, Brno, Czech Republic, 65-68.

NEXIS software. 2006. Software manual. 174 p.

Pasternak, P. L. 1954. Osnovy novogo metoda rascheta fundamentov na uprugom osnovanii pri pomoshchi dvukh koefficientov posteli [Principles of the New Method for Calculation of Foundations at the Elastic Subsoil Using Two Stiffness Coefficients]. Moskva: GILSA. 235 p.

Rasiulis, K.; Gurkšnys, K. 2010. Analyses of the stress intensity of the cylindrical tank wall at the place of the geometrical defect, Journal of Civil Engineering and Management 16(2): 209-215. http://dx.doi.org/10.3846/jcem.2010.23

STN 731001 Slovak National Standard Základová pôda pod plošnými základmi [Foundation Soil Below the Foundation Structures]. Bratislava: SÚTN, 2010. 26 p.

Vlasov, V. Z.; Leontiev, N. N. 1960. Balki, plity i obolochki na uprugom osnovanii [Beams, Plates and Shells on the Elastic Subsoil]. Moskva: GIFML. 491 p.

Zora MISTRíKOVÁ. Assoc. Prof., PhD. Department of Structural Mechanics, Slovak University of Technology in Bratislava, Faculty of Civil Engineering. She is author and co-author of 8 university textbooks and more than 50 scientific papers published in journals and proceedings. Research interests: interaction between the structure and the subsoil, contact problems and their applications for building engineering practice.

Norbert JENDŽELOVSKÝ. Prof., PhD at Department of Structural Mechanics, Slovak University of Technology in Bratislava, Faculty of Civil Engineering. He is author and co-author of 6 university textbooks and more than 40 scientific and special papers published in journals and proceedings. Four PhD. students have graduated under his supervising. Active member of several professional commissions. Research interests: modeling of the interaction between the structure and the subsoil, subsoil improvement methods. Presently holding the office of the Head of the Department. 